PressAcademia Procedia

\title{
ANALYZING WOMAN EXECUTIVES' POLITICAL SKILLS ACCORDING TO THE AGE FACTOR
}

\author{
DOI: $10.17261 /$ Pressacademia.2018.880 \\ PAP- V.7-2018(33)-p.198-203
}

Tugce Isler ${ }^{1}$, Yonca Bir ${ }^{2}$, Murat $\mathrm{Koc}^{3}$

${ }^{1}$ Cag University, Adana, Turkey. tugceisler13@gmail.com, ORCID: 0000-0003-4642-8021

${ }^{2}$ Cag University, Adana, Turkey. yoncabir@cag.edu.tr, ORCID: 0000-0002-4977-4010

${ }^{3}$ Cag University, Adana, Turkey.

muratkoc@cag.edu.tr, ORCID: 0000-0002-3848-3111

To cite this document

Isler, T., Bir, Y., Koc, M. (2018). Analyzing woman executives' political skills according to the age factor. PressAcademia Procedia (PAP), V.7, p.198-203.

Permanent link to this document: http://doi.org/10.17261/Pressacademia.2018.880

Copyright: Published by PressAcademia and limited licenced re-use rights only.

\section{ABSTRACT}

Purpose- The purpose of the study is to identify the impact of age factor on different political skills of woman executives' (networking, interpersonal influence, social intelligence and sincere appearance) that use in the power struggle in organizations.

Methodology- Data were collected from 125 woman executives' in the banking sector by the "purposive sampling method". To measure political skills of woman executives', Political Skill Inventory (PSI) were used. One way ANOVA method was used for examining the effect of age factor on political abilities.

Findings- As per results of the study the age is an important factor that affects the political skills of woman executives'. The relationships of woman executives' with interpersonal influence differ significantly by age factor.

Conclusion- Effects of the age factor of sub dimensions of woman executives' political skills are explained through the experience that woman achieved throughout the work period and the perceptive change which develops positively as the age progresses. The research is significant as it emphasizes age factor - as it is not frequently mentioned in the literature- which affects sub dimensions of woman executives' political skills.

Keywords: Organization, woman executives, political skills, age factor.

JEL Codes: J50, J53, M54

\section{KADIN YÖNETICILERIN POLITIK BECERILERININ YAŞ FAKTÖRÜNE GÖRE INNCELENMESI}

\section{ÖZET}

Amaç- Bu çalışmanın amacı kadın yöneticilerin örgütlerdeki güç mücadelesinde kullandıkları farklı politik becerilerinin (ilişki ağı kurma, kişiler arası etki, sosyal zeka, samimi görünme) yaş faktörüne bağlı olarak farklılık gösterip göstermediğini tespit etmektir.

Yöntem- Bu çalışma amaçlı örneklem yöntemiyle belirlenen Çukurova Bölgesinde bankacılık sektöründe çalışan 125 kadın yönetici ile yapılmıştır. Kadın yöneticilerinin politik becerilerinin belirlenmesi amacıyla katılımcılara "Politik Beceri Envanteri" uygulanmıştır. Kadın yöneticilerin farklı politik becerilerinin yaş faktörüne bağlı olarak farklılığının incelenmesinde Tek Yönlü ANOVA analizi uygulanmıştır.

Bulgular- Yapılan analizler sonucunda yaş faktörünün kadın yöneticilerin politik becerilerine etki eden önemli bir faktör olduğu tespit edilmiş, kadın yöneticilerin kişilerarası etki becerisinin yaşa göre anlamlı farklılık gösterdiği bulgusuna ulaşılmıştır.

Sonuç- Yaşın kadın yöneticilerin politik yeteneklerinin alt boyutları üzerindeki etkisi, kadınların çalışma dönemi boyunca elde ettikleri tecrübe ve yaşları ilerledikçe pozitif yönde gelişen algısal değişimle açıklanmıştır. Çalışma, literatürde sıklıkla yer almayan, ancak kadın yöneticilerin politik yeteneklerinin alt boyutlarını etkilediği değerlendirilen yaş faktörünün vurgulanması açısından önemlidir.

Anahtar kelimeler: Örgüt, kadın yönetici, politik beceri, yaş.

JEL Kodları: J50, J53, M54 


\section{GiRiş}

Kadının ilk olarak emeğini bir ücret karşılığı vermesi, dünyadaki tüm toplumları derinden etkileyen sanayi devrimi ile başlamıştır. Yaşanan sosyo-ekonomik gelişmeler, toplumsal bakış açısını da yönlendirerek kadına aile içinde ve toplumda yeni roller yüklemiştir. Böylece artık kadın, dış dünyada yani, iş yaşamında yerini yavaş yavaş almaya başlamıştır.( Kocacık, Gökkaya, 2005).

Sürekli değişen ve karmaşık hale gelen iş dünyasında sayısı gün geçtikçe artan ve etkisi daha fazla hissedilmeye başlanan her seviyedeki kadın yöneticilerin, genel yöneticilik ve liderlik faaliyetleri bağlamında kişileri etkileme becerileri gün geçtikçe önemli hale gelmektedir. İletişim becerileri ve bu becerinin geliştirilmesi ile ilgili yapılan akademik araştırma ve eğitsel çalışmalarda sadece cinsiyetler arasında anlamlı farkların olduğu görülmektedir.

Çeşitli araştırma bulgularıyla paralellik gösterir biçimde kız öğrencilerin erkeklere ve kadınların erkeklere göre iletişim becerilerini daha olumlu algıladıklarına dair biyolojik kökenli tespitler yanında, literatür de iletişim becerileri konusunda kadınların daha iyi olmalarını sosyalleşme ile de açıklayan çeşitli görüşler mevcuttur (Black, 2000; Korkut, 1996c, 1997; Reed, McLeod ve McAllister, 1999).

Farklılıklar ve uyuşmazlıkların dışında iş hayatında yaşanan hızlı değişimlerin varlığı, örgüt içindeki güç ve çıkar çatışmaları, geleceğin öngörülmez oluşu örgüt içindeki çalışanların politik davranışlarda bulunmalarına kaynaklık etmektedir. İşletmeler arası rekabetin arttığı günümüz şartlarında, yöneticilerin çevrelerini doğru analiz edebilmeleri, karmaşık durumları doğru gözlemleyebilmeleri, karmaşık durumlara uyum sağlayabilmeleri ve ortaya çıkan durumlardan fayda sağlamaya odaklanmaları oldukça önemli hale gelmiştir. Bütün bu gerekliliklere baktığımızda, karşımıza politik yeti kavramı çıkmaktadır. Örgütleri karmaşık hale getiren bu yapı, örgüt çalışanlarının çıkarlarını maksimize edecek veya örgüt içi negatif sonuçlardan korunmalarını sağlayacak çabalara yönelmelerinin de gerekçesini oluşturmaktadır. Politik yeti, iş ortamında diğer kişileri doğru şekilde analiz edebilmek ve bu bilgiyi kişisel ve örgütsel amaçlara ulaşabilmek için etkin şekilde kullanabilmektir (Blass ve Ferris, 2007).

\section{LITERATÜR INCELENMESI}

\subsection{Politik Davranış}

Politika kavramı içerik olarak son derece kapsamlıdır ve bu anlamda söylenen birçok söz, sergilenen birçok davranış ve hatta kimi zaman söylenmeyen sözler ile sergilenmeyen davranışlar bile politika ile ilişkilendirilebilmektedir. Herhangi biri tarafından politik olarak değerlendirilen bir davranış veya olay, bir diğer kimse için politik olma özelliğini taşımamaktadır. Bunun nedeni, örgütlerde yer alan bireylerin farklı algılamalara, anlayışlara ve çıkarlara sahip olmalarıdır ki tüm bu farklılıklar örgütleri politikleştirmektedir (Willcocks, 1994).

Politik davranış, "çalışanın resmi rolünün bir parçası olarak görülmeyen ancak onu etkileyen veya etkilemeye çalışan, örgüt içerisinde avantajların ve dezavantajların dağıtımına ilişkin faaliyetlerden oluşan bir süreç”olarak tanımlanmaktadır (Robbins ve Judge, 2013).

Örgütsel yaşamın ve dolayısıyla örgütsel davranışın bir türü olan politik davranışların genel bir amacı, örgüt üyesinin örgüt ortamındaki kişisel kontrolünü görece koruması ve güçlendirmesi biçiminde düşünülebilir. Böylece örgüt üyesi, örgütsel yaşama özgü çeşitli stres kaynaklarının olumsuz etkilerini daha az hissetmektedir (Harrell-Cook, Ferris ve Dulebohn, 1999).

\subsection{Politik Beceri}

Politik davranışların sonuca ulaşması politik becerileriyle ilişkilidir. Politik beceri düzeyi yüksek çalışanlar, iş yerindeki değişimlere çabuk uyum sağlayabilmekte, diğerlerine samimi ve içten davranarak onların desteğini ve güvenini kazanmakta ve böylece onları etkileyerek kontrol altına alabilmektedir. Politik beceriye sahip çalışanlar söz konusu etkiyi ve kontrolü, iş yerinde açık ve aleni davranışlar sergilemekten daha çok, bunu diğerlerine hissettirmeden sağlayabilmektedirler (Ferris, Treadway, Kolodinsky, Hochwarter, Kacmar, Douglas ve Frink, 2005).

Politik beceri, dinamik dünyada ve karmaşık durumlarda politik bilinçlilik, politik beceriklilik, politik zekâ veya sağduyulu olma kavramları, yöneticilerin ve liderlerin politik farkındalıkları için ihtiyaçları olan yetiyi tanımlamada ya çok eksik ya da çok fazla kalmaktadırlar. Politik beceri terimini kullanan ilk araştırmacılardan biri olan Pfeffer (1981), başarılı olmak için mutlaka politik yetiye ihtiyaç olduğunu ileri sürmüştür.

Politik beceri kavramı, genel olarak çıkarcılık gibi hoş karşılanmayacak kavramları akla getirdiğinden kötü bir şöhrete sahiptir. İnsanlar, kötü niyetli bir çıkar sağlama girişiminde oldukları zaman yeteneklerini kullanabilirler; ama politik yeti tamamen farklı bir konudur. Ferris ve arkadaşlarına (Ferris, Davidson ve Perrewe, 2005) göre politik yeti, pozitif bir güçtür ve günümüzde başarı için son derece gereklidir. "Politik beceriye sahip kişiler, başarıyı yakalamak için ne yapmak gerektiğini ve bunun, içten ve inandırıcı bir şekilde nasıl yapılması gerektiğini bilirler. Bununla birlikte bu kişiler, isteklerine ulaşabilmek ve avantaj sağlayabilmek için kendilerini doğru yerde ve zamanda konumlandırabilme özelliğine de sahiptirler" (Ferris vd, 2005)

Politik beceri, diğer bireyleri etkilemek için samimiyet ve doğruluk uyandıran cazip ve sempatik bir tavır içinde; sosyal zekâ, iyi ilişki kurma ve davranışlarını farklı durumlara göre ayarlayabilme yeteneğini kombine eden, sosyal bir yetenektir (Ferris vd. 2005). Bu tanıma göre, politik becerinin temel amacı başkalarını etkilemektir. Ferris ve arkadaşları 2005 yılında politik beceriyi dört alt boyutta incelemiştir.

Sosyal Zeka: Sosyal zeka, durumsal farkındalığa benzer. Sosyal zekaya sahip bireyler, farklı ve değişen durumlar karşısında nasıl davranacaklarını bilirler ve davranışlarını bunlara göre ayarlayabilirler (Blass ve Ferris, 2007; Blickle, 2011). Sahip oldukları sosyal zekâ onların, değişik sosyal ortamlarda diğer kişi ve gruplarla uygun şekilde etkileşime girmelerini sağlar (Blass ve Ferris, 2007).

Kişiler arası etki: Kişilerarası etki, diğer insanlarla arzulanan değişimler oluşturabilme becerisi olarak ifade edilir. Bu yeteneğe sahip kişiler, başkaları üzerinde güçlü bir etkiye sahiptirler (Blickle, Oerders, Summers., 2010b). İnsanları ikna etme konusunda sorun yaşamazlar. Politik 
olarak yetenekli kişilerin, başkaları üzerinde güçlü bir etki yaratmalarına yol açan temel unsur, bireyleri etkilemeyi daha kolay hale getiren çekici bir kişisel tarza sahip olmalarıdır (Blass ve Ferris, 2007).

İlişki ağı oluşturma: îlişki ağı oluşturma veya sosyal sermaye, örgüt içinden ve dışından çeşitli ağlara ulaşabilmeyle alakalı bir durumdur (Treadway, Breland, Adams, Duke, Williams, 2010). Politik yeteneklere sahip olan kişiler güçlü ve faydalı ilişkiler ve ortaklıklar-ağlar kurabilme, bu ağlardan faydalanma ve ağları koruma konusunda etkilidirler.

Dürüst ve Samimi Görünme: Yüksek düzeyde doğruluk, dürüstlük, güvenirlilik, içtenlik ve samimiyet. Politik yeteneklere sahip olan kişilerin davranışları, sahip oldukları sosyal zekâya bağlı olarak, manipülatif veya zorlayıcı olarak algılanmaz.

\section{VERI VE YÖNTEM}

Bu araştırmanın amacı kadın yöneticilerin örgütlerdeki güç mücadelesinde kullandıkları farklı politik becerilerinin (ilişki ağı kurma, kişiler arası etki, sosyal zeka, samimi görünme) yaş faktörüne bağlı olarak farklılık gösterip göstermediğini tespit etmektir. Bu doğrultuda araştırmanın modeli aşağıdaki gibi tasarlanmıştır.

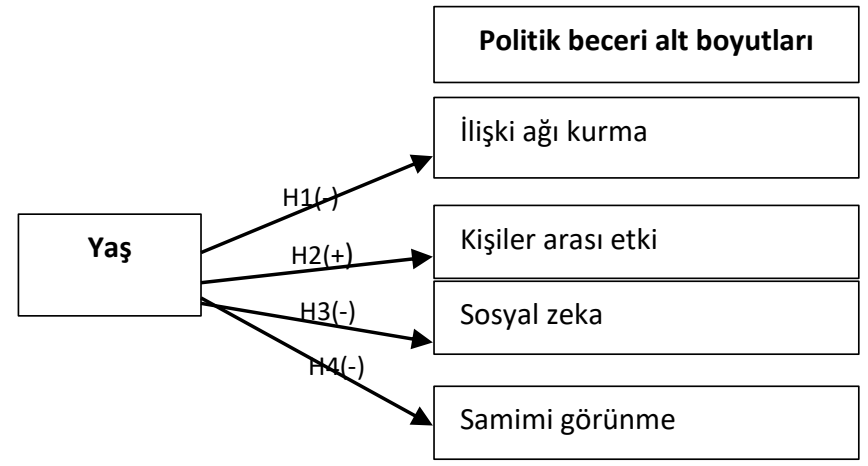

H1: Kadın yöneticilerin politik becerilerinden ilişki ağı kurma alt boyutu yaşa göre farklılık göstermektedir.

H2: Kadın yöneticilerin politik becerilerinden kişiler arası etki alt boyutu yaşa göre farklılık göstermektedir.

H3: Kadın yöneticilerin politik becerilerinden sosyal zeka alt boyutu yaşa göre farklılık göstermektedir.

H4: Kadın yöneticilerin politik becerilerinden samimi görünme alt boyutu yaşa göre farklılık göstermektedir.

Araştırmanın ana kütlesini Adana ili bankacılık sektöründe faaliyet gösteren üst, orta ve alt düzey yönetici kademelerinde çalışan kadın yöneticiler oluşturmaktadır. Örneklem ise ana kütleden amaçlı örneklem yöntemiyle seçilmiş, farklı düzeydeki 125 kadın yöneticiden oluşmaktadır. Araştırmada veri toplama aracı olarak 2 bölüm toplamda 22 sorudan oluşan anket formu kullanılmıştır. Birinci bölümde, kadın yöneticilerin demografik özellikleri ile ilgili sorular (yaş, yöneticilik düzeyi, çalışma süresi, medeni durum) bulunmaktadır. İkinci bölümde, Ferris ve ark. (2005) tarafından geliştirilen 18 ifadeli Politik Beceri Envanteri (PBE) kullanılmıştır. Türkçe’ye çevirisi Özdemir ve Gören (2015) tarafından yapılan ölçeğin faktör analizi için gerekli olan KMO (Kaiser-Mayer-Olkin) örneklem yeterlilik katsayısı 0.92 olarak hesaplanmış ve Barlett Küresellik testi anlamlı bulunmuştur $(p<0,001)$. Açıklanan varyans tablosu özdeğeri 1 ve daha üzeri olan 4 bileşen ortaya çkarmıştır. Dört faktörün açıkladığı toplam varyans \%74'tür. Dört faktör altında toplanan maddelerin PBE'nin orjinali ile uyumlu olduğu gözlemlenmiştir. Ölçeğin Cronbach's Alpha güvenilirlik katsayısı ise 0.94 olarak bulunmuştur. Alt boyutlara ilişkin Cronbach's Alpha katsayıları ise; îlişki Ağı Kurma Becerisi boyutu için .86, Kişilerarası Etki boyutu için .92, Sosyal Zeka boyutu için .87 ve Samimi Görünme boyutu için .88 olarak hesaplanmıştır. Bu bulguya göre PBE'nin dört boyutlu Türkçe versiyonunun güvenilir olduğu anlaşılmıştır. Araştırma için belirlenen ölçme araçlarıyla elde edilen veriler SPSS 20.0 istatistik paket programı ile analiz edilmiştir. Elde edilen verilerin analizinde ölçek güvenilirliği, demografik özelliklerinin frekans ve yüzde dağılımları, ölçek puanlarının yaşa göre farklılaşma durumlarının incelenmesinde tek yönlü varyans analizi(ANOVA) analizi tekniklerinden yararlanılmıştır. ANOVA analizi sonrasında farklılıkları belirlemek üzere tamamlayıcı post-hoc analizi olarak LSD testi kullanılmıştır. Verilerin analiz edilmesinde, istatistik anlamlılıkta p<0.05 alınmıştır.

\section{BULGULAR}

Kadın yöneticilerin demografik özelliklerine ilişkin elde edilen bilgiler şu şekilde özetlenebilir: Katılımcıların çoğunluğunu (\%65) 25-35 yaş aralığında, (\%73) orta düzey kademesinde yönetici, (\%58) 6-15 yıl arası çalışan ve (\%73) evli yöneticiler oluşturmaktadır. Bu araştırmanın analizinde kullanılan SPSS 22.0 programında ölçek sorularına ilişkin yapılan güvenilirlik analizi sonuçlarına göre hesaplanan Cronbach's Alpha katsayısı olarak 0.857 değeri elde edilmiştir. Ölçeğin alt boyutlarına ilişkin hesaplanan Cronbach's Alpha katsayıları ise; İlişki Ağı Kurma Becerisi boyutu için 0.690, Kişilerarası Etki boyutu için 0.763, Sosyal Zeka boyutu için 0.694 ve Samimi Görünme boyutu için 0.538 olarak hesaplanmıştır. Kalaycı (2008)'e göre 0 ile 1 arasında değer alan alfa katsayısına bağlı olarak ölçeğin güvenilirliği şu şekilde yorumlanabilir: $0,00 \leq \alpha<0,40$ ise ölçek güvenilir değildir; $0,40 \leq \alpha<0,60$ ise ölçeğin güvenilirliği düşük; $0,60 \leq \alpha<0,80$ ise ölçek oldukça güvenilir ve $0,80 \leq \alpha<1,00$ ise ölçek yüksek derecede güvenilirdir. Bu bilgiler ışığında elde edilen Cronbach alfa değerleri incelendiğinde İlişki Ağı Kurma, Kişiler Arası Etki ve Sosyal Zeka boyutları oldukça güvenilir bulunurken, Samimi Görünme boyutunun güvenilirliğinin düşük olduğu gözlemlenmiştir. Ölçeğin genelinin ise yüksek derecede güvenilir olduğu sonucuna ulaşılmıştır. 
Tablo 1: Ölçeklere İlişkim Güvenirlik Analizi

\begin{tabular}{|l|c|c|}
\hline Ölçek & Cronbach's Alfa & Soru Sayısı \\
\hline Politik Beceri Envanteri (Total) & 0,857 & 18 \\
\hline İlişki Ağı Kurma & 0,690 & 6 \\
Kişiler Arası Etki & 0,763 & 4 \\
Sosyal Zeka & 0,694 & 5 \\
Samimi Görünme & 0,538 & 3 \\
\hline
\end{tabular}

Araştırmaya katılan kadın yöneticilerin kişiler arası etki boyutunun yaş değişkenine göre anlamlı bir farklılık gösterip göstermediğini belirlemek amacıyla yapılan tek yönlü varyans analizi (Anova) sonucunda grup ortalamaları arasındaki fark istatistiksel açıdan anlamlı bulunmuştur $(F=8,423 ; p=<0.001)$. Farklılıkların kaynaklarını belirlemek amacıyla tamamlayıcı post-hoc analizi yapılmıştır. Yaşı 36-45 yaş olanların kişiler arası etki puanları $(4,458 \pm 0,420)$, yaşı $25-35$ yaş olanların kişiler arası etki puanlarından $(4,111 \pm 0,586)$ yüksek bulunmuştur. Yaşı 46-55 yaş olanların kişiler arası etki puanları $(4,533 \pm 0,485)$, yaşı 25-35 yaş olanların kişiler arası etki puanlarından $(4,111 \pm 0,586)$ yüksek bulunmuştur.

Araştırmaya katılan kadın yöneticilerin ilişki ağı kurma $(p=0,267 ; p>0.05)$, sosyal zeka( $p=0.126 ; p>0.05)$ ve sosyal zeka( $p=0.524 ; p>0.05)$ boyutlarının yaş değişkenine göre anlamlı bir farklılık gösterip göstermediğini belirlemek amacıyla yapılan tek yönlü varyans analizi (Anova) sonucunda grup ortalamaları arasındaki fark istatistiksel açıdan anlamlı bulunmamıştır.

Tablo 1: Politik Beceri Puanlarının Yaşa Göre Ortalamaları

\begin{tabular}{|c|c|c|c|c|c|c|}
\hline & Grup & $\mathbf{N}$ & Ort & Ss & $\mathbf{F}$ & $\mathbf{p}$ \\
\hline \multirow{3}{*}{ İlişki Ağı Kurma } & 25-35 Yaş & 65 & 4,230 & 0,467 & \multirow{3}{*}{1,334} & \multirow{3}{*}{0,267} \\
\hline & 36-45 Yaş & 30 & 4,305 & 0,394 & & \\
\hline & 46-55 Yaş & 30 & 4,388 & 0,440 & & \\
\hline \multirow{3}{*}{ Kişiler Arası Etki } & 25-35 Yaş & 65 & 4,111 & 0,586 & \multirow{3}{*}{8,423} & \multirow{3}{*}{$0,000 * *$} \\
\hline & 36-45 Yaş $^{\mathrm{a}}$ & 30 & 4,458 & 0,420 & & \\
\hline & 46-55 Yaş $^{\mathrm{a}}$ & 30 & 4,533 & 0,485 & & \\
\hline \multirow{3}{*}{ Sosyal Zeka } & 25-35 Yaş & 65 & 4,064 & 0,491 & \multirow{3}{*}{2,108} & \multirow{3}{*}{0,126} \\
\hline & 36-45 Yaş & 30 & 4,093 & 0,508 & & \\
\hline & 46-55 Yaş & 30 & 4,300 & 0,625 & & \\
\hline \multirow{3}{*}{ Samimi Görünme } & 25-35 Yaş & 65 & 4,292 & 0,505 & \multirow{3}{*}{0,649} & \multirow{3}{*}{0,524} \\
\hline & 36-45 Yaş & 30 & 4,200 & 0,459 & & \\
\hline & 46-55 Yaş & 30 & 4,344 & 0,528 & & \\
\hline
\end{tabular}

\section{SONUÇ}

Son otuz yılda ortaya çıkan ve araştırmacıların dikkatini çeken konulardan biri haline gelerek gelişim gösteren örgütsel politika, "başkalarını başarılı şekilde etkileme potansiyeli olan gücün eyleme dönüştürülmesi sürecini ele alması” sebebiyle özellikle yöneticiler için oldukça önem arz etmektedir (Atay,2010).Pfeffer (1981) ve Mintzberg (1983) tarafından örgütler politik bir bakış açısıyla ele alınarak, her bir örgütün politik bir arena olduğu tanımlanmıştır. Örgütlerin etkili ve verimli bir şekilde hayatlarını sürdürebilmeleri için politik yetiye sahip olmaları gerektiğini savunmuşlardır. Yönetim alanının güç ve politika başlığı altında yükseliş gösteren kavramlardan biri olan politik yeti (Atay,2010), Ferris, Treadway vd. (2005) tarafından "işyerinde başkalarını etkin şekilde anlama, başkalarını etkileme bilgisini kullanma ve başkalarının kişisel ve örgütsel hedeflerini zenginleştirecek şekilde davranma” olarak ele alınarak dört temel boyut(network yeteneği, kişiler arası etki, sosyal beceriklilik, içtenlik) üzerinden tanımlanmıştır. Bu çalışmanın amacı kadın yöneticilerin örgütlerdeki güç mücadelesinde kullandıkları farklı politik becerilerinin (ilişki ağı kurma, kişiler arası etki, sosyal zeka, samimi görünme) yaş faktörüne bağlı olarak farkılık gösterip göstermediğini tespit etmektir.

Yapılan analizler sonrasında elde edilen araştırma sonuçlarına göre sadece kișiler arası etki boyutunda yaș faktörüne göre anlamlı farklılaşma tespit edilmiştir. Bu bulgudan hareketle, araştırmanın H2 hipotezi desteklenirken; H1,H3,H4 hipotezleri araştırma sonuçlarıyla desteklenmemiştir. Yaşı 46-55 ve 36-45 aralığında olan kadın yöneticilerin kişiler arası etki puanlarının yaşı 25-35 aralığında olanlardan daha yüksek olduğu gözlemlenmiştir. Ayrıca politik becerilerin diğer demografik özelliklere göre farklılaşma durumları incelendiğinde; ilişki ağı kurma $(p<0.001)$, kişiler arası etki $(p<0.001)$ ve sosyal zeka $(p<0.001)$ boyutlarının yöneticilik düzeyi değişkenine göre; ilişki ağı kurma $(p=0.025 ; p<0.05)$, kişiler arası etki $(p<0.001)$ ve sosyal zeka $(p<0.001)$ boyutlarının çalışma süresi değişkenine göre anlamlı farklılık gösterdiği bulunurken, samimi görünme boyutunun yöneticilik düzeyi ( $p=0.063 ; p>0.05)$ ve çalışma süresi $(p=0.215 ; p>0.05)$ değişkenlerine göre anlamlı farklılık göstermediği sonucuna ulaşılmıştır. Medeni durum değişkeni ile politik beceri boyutları arasında ise anlamlı bir farklılaşma gözlemlenmemiştir; ilişki ağı kurma ( $p=0.923 ; p>0.05)$, kişiler arası etki( $p=0,844 ; p>0.05)$, sosyal zeka( $p=0,854 ; p>0.05)$, samimi görünme $(0,819 ; p>0.05)$. Eğitim durumu değişkeni ile politik beceri boyutları arasında da anlamlı bir farklılaşma tespit edilmemiştir; ilişki ağı kurma ( $p=0.537 ; p>0.05)$, kişiler arası etki $(p=0,386 ; p>0.05)$, sosyal zeka( $(p=0,826 ; p>0.05)$, samimi görünme $(0,338 ; p>0.05)$. Elde edilen 
bulgular doğrultusunda; üst düzey yönetici kademesinde çalışan 6-15 yıl arasında deneyime sahip kadın yöneticilerin ilişki ağı kurma, kişiler arası etki ve sosyal zeka becerilerinin daha yüksek olduğu sonuçlarına ulaşılmıştır. Bu kapsamda şirketteki çalışma süresi ile birlikte ele alındı̆̆ında yöneticilik düzeyleri, yaşla birlikte yükselen kadın yöneticilerin şirket kültürü ile uyum ve devam bağlılı̆ın bir göstergesi olan çalışma süreleri arttıkça politik becerilerinin arttı̆̆ı sonucuna ulaşılıışır. Ayrıca, $46-55$ yaş grubundaki kadın yöneticilerinin pre-peri ve post menopoz döneminde oldukları göz önünde bulundurulduğunda, biyolojik olarak yaşadıkları değişim ve yönetsel farkındalıklarının sosyal rollerindeki değişimlerle beraber politik becerilerinin kişilerarası etkileşime doğrudan yansıdığı sonucuna varılmıştır. Sonuç olarak; yaşın kadın yöneticilerin politik yeteneklerinin alt boyutları üzerindeki etkisi, kadınların çalışma dönemi boyunca elde ettikleri tecrübe ve yaşları ilerledikçe pozitif yönde gelişen algısal değişimle açıklanmıştır. Ölçeğin geneli ve alt boyutlar arasındaki ilişkiler incelendiğinde ise; politik beceri envanteri (total) ile ilişki ağı boyutu arasında pozitif yönlü yüksek düzeyde anlamlı bir ilişki $(r=0,799 ; p<0.001)$, kişiler arası etki boyutu ile pozitif yönlü yüksek düzeyde anlamlı bir ilişki $(r=0,809 ; p<0.001)$, sosyal zeka boyutu ile pozitif yönlü yüksek düzeyde anlamlı bir ilişki $(r=0,842 ; p<0.001)$, samimi görünme ile pozitif yönlü orta düzeyde anlamlı bir ilişki $(r=0,655 ; p<0.001)$ bulunmuştur. Elde edilen bu bulgulardan hareketle ilişki ağı, kişiler arası etki ve sosyal zeka boyutlarının politik becerinin geneli ile daha yüksek ilişkili olduğu sonucuna ulaşıımışır. Boyutların birbirleri ile olan ilişkisi değerlendirildiğinde; ilişki ağı kurma ve kişiler arası etki boyutu arasında pozitif yönlü orta düzeyde anlamlı bir ilişki $(r=0,538 ; p<0.001)$, ilişki ağı kurma ve sosyal zeka boyutu arasında pozitif yönlü orta düzeyde anlamlı bir ilişki $(r=0,508 ; p<0.001)$, ilişki ağı kurma ve samimi görünme boyutu arasında pozitif yönlü zayıf düzeyde anlamlı bir ilişki $(r=0,332 ; p<0.001)$, kişiler arası etki ve sosyal zeka boyutu arasında pozitif yönlü orta düzeyde anlamlı bir ilişki $(r=0,558 ; p<0.001)$, kişiler arası etki ve samimi görünme boyutu arasında pozitif yönlü orta düzeyde anlamlı bir ilişki $(r=0,428 ; p<0.001)$, sosyal zeka ve samimi görünme boyutu arasında pozitif yönlü orta düzeyde anlamlı bir ilişki $(r=0,508 ; p<0.001)$ tespit edilmiştir. Bu bulgular neticesinde kişiler arası etki ve sosyal zeka boyutları birbirleriyle daha ilişkilidir. En zayıf ilişki ise ilişki ağı kurma ve samimi görünme boyutları arasındaki ilişkidir. Elde edilen bulgular literatürle uyumludur(Ferris vd.,2009; Ferris vd., 2005; Kara, 2016). Araştırmanın bir diğer bulgusu da samimi görünme boyutunun güvenilirliğinin düşük olmasıdır. Bu bulgulardan hareketle kadın yöneticilerin örgüt amaçları doğrultusunda örgüt içi koalisyonlar kurmak maksadıyla çevrelerine daha iyi görünebilmek ve çeşitli ağları kullanarak kolayca yeni arkadaşlar edinebilmek için samimi davrandıkları söylenebilir. Çünkü art niyet taşıdıı̆ına ilişkin bir izlenim veren kişiler, başkalarını etkileme gücünü kaybedecektir (Atay, 2010; Blass ve Ferris, 2007; Ferris vd., 2005). Alan yazında politik yetinin çeşitli değişkenlerle olan ilişkisinin incelendiği çalışmalara da rastlanmaktadır (Atay, 2010; Kara, 2016).Çalışma, literatürde sıklıkla yer almayan, ancak kadın yöneticilerin politik yeteneklerinin alt boyutlarını etkilediği değerlendirilen yaş faktörünün vurgulanması açııından önemlidir. Ayrıca Özdemir ve Gören'in (2015) eğitim örgütlerinde uyarlamasını yaptıkları ölçeğin bu araştırmada farklı bir örneklem üzerinde kullanılmasının alan yazına katkıda bulunacağı düşünülmektedir.

\section{KAYNAKÇA}

Atay, S. (2010). Geliştirilebilir yönetim becerisi: teorik ve ampirik yönleriyle politik yeti. Amme İdaresi Dergisi, c. 43, s. 2, s. 65-80.

Black, K. A. (2000). Gender differences in adolescents' behavior during conflict resolution tasks with best friends. Adolescence, vol .35, no. 139, p. 499-512.

Blass, F. R., Ferris, G. R. (2007). Leader reputation: the role of mentoring, political skill, contextual learning, and adaptation. Human Resource Management, vol. 46, no. 1, p. 5-19.

Blickle, G., Oerder, K., Summers, J. K. (2010b). The impact on political skill on career success of employees' representatives. Journal of Vocational Behavior, vol. 77, p. 383-390.

Blickle, G. (2011). Socioanalytic theory and work behavior: roles of work values and political skill in job performance and promotability assessment. Journal of Vocational Behavior, vol. 79, no. 1, p. 136-148.

Douglas T. Hall. (1990). Career development theory in organizations (S. Artaç, Trans.). Mc. Graw Hill.

Ferris, G. R., Berkson, H. M. Kaplan, D. M., Gilmore, D. C., Buckley, M. R., Hochwarter, W. A., Witt, L. A. (1999). Development and initial validation of the political skill inventory. Paper presented at the Academy of Management, , Chicago (59th Annual National Meeting).

Ferris, G. R., Davidson, S. L., Perrewe, P.L. (2005). Political skill at work: Impact of effectiveness, organizational Dynamics. Davis-Black, CA, Palo Alto.

Ferris, G. R., Treadway, D. C., Kolodinsky, R. W., Hochwarter, W. A., Kacmar, C, J., Douglas, C., Frink, D. D. (2005). Development and validation of the political skill inventory. Journal of Management, vol. 31 no. 1, p. 126-152.

Harrel-Cook, G., Ferris, G. R., Dulebohn, J. H. (1999). Political behaviors as a moderator of the perceptions of organizational politics-work outcomes relationships. Journal of Organizational Behavior, vol. 20, no.7, p. 1093-1105.

Kalaycı, Ş. (2008). SPSS uygulamali çok değişkenli istatistik teknikleri. (3. Baskı). Ankara, Asil Yayın Dağıtım.

Kara, H. (2016). Yöneticilerin negatif politik değer eğilimlerini kullanma becerileri özelinde bir araştırma. UiiD-IJEAS, c. 16, s. 77-96.

Kocacık, F., Gökkaya, V. (2005). Türkiye'de çalışan kadınlar ve sorunları. C.Ü. İktisadi ve İdari Bilimler Dergisi, c. 6, s. 1, s. 195.

Korkut, F. (1996c). Lise öğrencilerinin bazı değişkenler açısından iletişim becerilerini değerlendirmeleri. 3. Ulusal Psikolojik Danışma ve Rehberlik Kongresi Bilimsel Çalışmaları. Çukurova Üniversitesi, s. 11-20

Korkut, F. (1997). Üniversite öğrencilerinin iletişim becerilerini değerlendirmeleri. IV Ulusal Eğitim Bilimleri Kongresi Bildirileri, Anadolu Üniversitesi, s. 208-218. 
Mintzberg, H. (1983). Power in and around organizations. Englewood Cliffs, NJ, Prentice Hall.

Özdemir, M., Gören, S. Ç. (2015). Politik beceri envanterinin eğitim örgütlerinde geçerlik ve güvenirlik çalışmaları. Kuram ve Uygulamada Eğitim Yönetimi, c. 21, s. 4, s. 521-536.

Pfeffer, J. (1981). Power in organizations. Boston, Pitman

Reed, V. A., McLeod, K., McAllister, L. (1999). Importance of selected communication skills for talking with peers and teachers: adolescent' opinions. Language Spech and Hearing Services in Schools, vol. 30, no. 1, p. 32-49.

Robbins, S. P., Judge, T. A. (2013). Organizational behaviour (i. Erdem, Trans.). Ankara, Nobel.

Sagrestano, L. M., (1992). The use of power and influence in a gendered world. Psychology of Women Quarterly, Vol.16, No.4, p. 446.

Treadway, D. C., Brealand, J. W., Adams, G. L., Duke, A. B., Williams, L. A. (2010). The interactive effects of political skill and future time perspective on career and community networking behavior. Social Networks, vol. 32, p. 138-147.

Willcocks, S. G. (1994). Organizational analysis: a health service commentary. Leadership and Organization Development Journal, Vol.15, No.1, s.31. 